\title{
The Indifferent, the Good Samaritan, the Brave and the Agent in Allais Paradox situation - or How Endowment Effect Influences Our Decision in Case of Allais Paradox?
}

\author{
Anita KOLNHOFER-DERECSKEI

\begin{abstract}
Obuda University, Faculty of Business and Management, Budapest, Hungary derecskei.anita@kgk.uni-obuda.hu
\end{abstract}

"The real substance on which the economist works remains economic and social." (Allais, 1988)

\begin{abstract}
Background and purpose: Mainstream economic models do not take ownership into consideration. Only after the findings of behavioural economists was endowment effect widely observed. Endowment effect means that goods that one owns are valued higher than other goods not held in endowment. At the same time the principal-agent literature is concerned with how the principal (such as employer) can motivate his agent (say the employee), to act in the principal's interests and also for their holdings. The main problem is that acting in somebody's else's interests can influence our values as well. Moreover, the principal as owner suffers from endowment effect. Both situations can be treated as a risky decision. Risk confuses our rationality in a predictable way.

Design/Methodology/Approach: Due to this it was observed how foreign students from various cultural backgrounds decided ( $n=186$ answers) in a risky financial situation by focusing on Allais' classic gambles. I also presented their preferences over certain and uncertain outcomes regarding the owner of the final win; i.e. how they choose for themselves or on behalf of one of their best friends. One famous experiment - which tested the descriptive validity of the axioms' expected utility theory - was Allais. Allais handled probabilities and outcomes in high hypothetical payoff financial gamble situations; he found that when offering two similar options, the common consequences will not be removed by the actors. I was interested in what happens when the actors take risks on behalf of others. It was used between-subjects technique on an extended multicultural sample. Regarding the two different topics, three hypotheses were tested (1); based on Allais paradox (2); observed ownerships (3); the comparison of two phenomena.

Results: The results show that the subjects responded differently when they needed to decide about their own properties rather when their friends' properties were concerned. When a sure safe outcome was offered to the subjects, they took more risk on behalf of their friends rather than own. Moreover, the subjects do not take into consideration that the same attributes must be ignored, so Allais paradox was verified.

Conclusion: The goal of this paper is then twofold. First, it was established a conceptual link between Allais-type behaviour and ownership problem. Second, Allais axiom was used to characterize different roles. Knowing predictable patterns of seemingly irrational heuristics in human behaviour can improve economic theory. At the same time, this knowledge helps us to avoid irrational decisions.
\end{abstract}

Keywords: Allais paradox; Endowment effect; Principal-Agent Problem; Risk

Received: July 11, 2017; revised: September 30, 2017; accepted: October 20, 2017 


\section{Introduction}

Nowadays, it is well-known that an average employee spends more than 25 percent of their working life deciding on others' interests. Despite the fact they take risks on behalf of others, i.e., are responsible for others' utilities maximizations, they try to do their best. They allocate scarce resources to satisfy others' wants and needs.

At the same time, not only economic resources are scarce, in addition, human psychological resources - like attention - are limited as well. Due to this, the profit-maximizations of the aforementioned employees are not accomplished; this is, in a part, because of the lack of complete information. In decision-making, the Nobel Prize winner Herbert Simon (1971) believed that agents face uncertainty about the future and costs in acquiring information in the present. These factors limit the extent to which agents can make a fully rational decision, thus they possess only "bounded rationality" and must make decisions by "satisficing," or choosing that which might not be optimal but which will make them or the owners happy enough. So they will use special heuristics (rules of thumbs based on previous experiences) which hurt the rationality of 'homo oeconomicus model act'. These two issues provide the importance and relevance of this experiment.

\subsection{Theoretical background}

\subsubsection{Expected utility theory}

Choosing rationally is equal to choosing the option with the higher expected utility (EU), defined as $\mathbf{E} \mathbf{U}=\sum \mathbf{u}\left(\mathbf{x}_{\mathrm{i}}\right)$ $\mathbf{p}_{\mathrm{i}}$ where $\mathrm{p}_{\mathrm{i}}$ and $\mathrm{x}_{\mathrm{i}}$ mean the probability and the amount of payoffs, $\mathrm{u}$ is the function of the payment, respectively, associated with each possible outcome $(\mathrm{i}=1, \ldots, \mathrm{n})$ of that option. Later, von Neumann \& Morgenstern (1947) explained expected-utility theory on axiomatic grounds; it quickly became the most influential theory of individual choice behaviour. (Hertwig et al. 2004). Assumptions of the expected utility theory were laid in the 1940s by Neumann and Morgenstern. They offered several simple axioms, characterizing preferences of rational actor, they suggested that the utility of a risky gamble should be the probability weighted average of the utilities of its possible outcomes (Camerer, 1998).

One of these axioms are the so called independence implies. The independence axiom shows how choice is influenced by only the differences among many alternatives, but the same attributes must be ignored. It means that, when comparing gambles, all common outcomes that have the same probabilities will be handled by the subjects as irrelevant. One famous experiment which tested the descriptive validity of the axioms of expected utility theory were the Allais' experiments. He found that under certain conditions subjects would violate this aforementioned in- dependence axiom. (Oliver, 2003). The Allais paradoxes were enough to cast some problem on Neumann and Morgenstern's theory.

As Hertwig et al. (2004) summarized "Perhaps the most prominent violation is the Allais paradox (...) in which decision makers choosing between risky prospects do not conform to the independence axiom, according to which outcomes common to all prospects (and with known probabilities) should have no influence on the decision." (p. 535)

The empirical testing, experimental methods became the focus of decision making. Because various studies began to propose ways to generalized Allais paradox to explain data. During this period, most scholars were tested by psychologists and covered on the interdisciplinary area between psychology and economics. Important work includes weighted utility theory, rank-dependent theory and finally the famous prospected theory (Kahneman \& Tversky, 1974). Most papers included an obligatory discussion of how their theories could explain the Allais paradox. There were a couple of datasets without clear conclusion, but the experimental methods served as models for researches. Camerer (1998) summarized some periods after Allais' finding. Only few of them are mentioned here, because those serve like limitations of the original Allais' problem and either this research. Some researchers have focused on fitting theories to personal characteristics (see later Palmer et al. 2013), and risk taking can be one of these characteristics. Estimation of uncertainty and probabilities are subjective (personal). In addition, they are revealed by choices. One's decisions are influenced by their earliest experiences; so-called subjective expected utility theories provided new experiments like Ellsberg "two color problem". Most experiments require people to weigh current problems against future outcomes, but those problems are relatively new and not likely or known by the subjects. Due to this, it seems that knowing how preferences are formed over time is also needed. Finally, it is important to understand the environment, and cultural background. Aforementioned findings brought new theories but importance of Allais paradox does not disappear.

\subsubsection{Allais paradox}

Allais used a standard gamble situation with money (financial) outcomes. The common consequence effect tested empirically how the subjects' choices violated independence. Allais argued that when the individuals are faced with the situations detailed in Table 1, they changed their preferences. Because, when we ignore common outcomes or consequences (i.e. outcomes with 0.89 probabilities), the outcome of Gamble A (in Case X) is equal to outcome of Gamble C (in Case Y); at the same time, Gamble B is equal to Gamble D. Despite of this most of the subjects chose Gamble A in Case X and Gamble D in Case Y. This 
Allais Paradox was tested between subjects (they were divided into two groups related to the cases, and only one case was offered) and within subjects (i.e. both cases were offered for each subject) methods, as well. Here, I used the between subjects technique.

The suggested amount of outcomes serves as a reference points for the actors. Huck \& Müller (2012) implemented three different treatments; one with the original version (high hypothetical payoffs); another with low hypothetical payoffs; and the last one with low but real payoffs. According to the authors, violations were systematic and significant, but much lower when outcomes (stakes) are low; also, these were much lower in a laboratory environment than on real fields. I agree with the authors who suggested that it would be more useful to study relative real outcomes rather than hypothetical absolute levels. Maybe changing the topic of the outcomes might solve this problem. However, Oliver (2003) tested it using health outcomes. He also verified Allais' paradox in his empirical testing (he used health outcomes with the classic probabilities). He found that this effect was stronger when the participants also gave extended possibilities to provide explanations. I agree with Khalil (2015), who provided a relatively new reason for Allais problem and connected Allais paradox with shoplifting. He wrote, "Regretting a rational decision means changing your belief about that decision so that what appeared optimal at the time now appears suboptimal. Concerning the Allais paradox (the certainty effect), it is the outcome of people's fear of regret. Fear of regret leads people to become over-cautious, using biased under-confident beliefs that lead them to compulsive behavior such as seeking zero-risk options." (Khalil, 2015, p. 551).

As a result, Huck \& Müller (2012) found significant differences between demographical characteristics of actors; consequently, the undergraduate persons with lower incomes were less consistent. Da Silva et al. (2013) asked
120 students biological and demographical background before testing Allais paradox. I think their small number and widely heterogenous sample does not cover the needed statistical pre-requirements. However, the authors found "that women, in particular if not menstruating, are more "rational" in that they are less susceptible to the Allais paradox. Those born to not-too-young mothers are more rational, too. Those who father kids are also more rational. Those with high prenatal testosterone exposure are more rational. Those with many negative life events are also more rational. Anxious, excited, alerted, happy, active, and fresh people are also more rational. Left-handers and atheists are possibly more rational, too." (Da Silva et al., 2013, p. 568). In my case, the limited size and non-representative sample did not allow testing deeper gender differences or family background, moreover, I did not focused in female respondents' menstrual cycle or answerers' mother's age, parenthood or digit ratio as Da Silva et al. (2013) did.

Van de Kuilen and Wakker (2006) tested empirically how Allais paradox works if subjects are given the opportunity to learn by both thought and experience. They argued that in both cases the number of expected utility violations decreased significantly because learning can reduce probability transformations. With reputation and feedback, subjects learned and avoided violations of expected utilities. In this experiment, no learning possibilities or feedback were given to the respondents. It used one of the typical lab online methods but did not control the influences of the environment. Only the number of decisions / choices were calculated quantitatively and there were no measurement of how aware people are of the decisions they make and how the environment influences these decisions.

It can be realized that if the common consequences (i.e. highlighted column in Figure 1) are removed Case X is equal to Case Y. However, if we consider all probabilities, it can also be realized that Case $\mathrm{X}$ is not risky because it contains a safe option with a sure outcome (Gamble A).

Table 1: Allais' paradox, where independences are highlighted (Own source)

\begin{tabular}{|c|c|c|c|c|c|c|}
\hline & & & \multicolumn{3}{|c|}{ Probabilities } & \\
\hline Case X & winnings & probability & 0,1 & 0,89 & 0,01 & \multirow{5}{*}{ 寻 } \\
\hline Gamble A & 100 & 1 & 100 & 100 & 100 & \\
\hline \multirow{3}{*}{ Gamble B } & 100 & 0,89 & \multirow{3}{*}{500} & \multirow{3}{*}{100} & \multirow{3}{*}{0} & \\
\hline & 500 & 0,1 & & & & \\
\hline & 0 & 0,01 & & & & \\
\hline Case Y & winnings & probability & 0,1 & $\mathbf{0 , 8 9}$ & 0,01 & \multirow{5}{*}{ 青 } \\
\hline \multirow{2}{*}{ Gamble C } & 100 & 0,11 & 100 & $\mathbf{0}$ & 100 & \\
\hline & 0 & 0,89 & \multirow{3}{*}{500} & \multirow{3}{*}{ 0 } & \multirow{3}{*}{0} & \\
\hline \multirow{2}{*}{ Gamble D } & 500 & 0,1 & & & & \\
\hline & 0 & 0,9 & & & & \\
\hline
\end{tabular}


Table 1, which is based on the classic, original Allais experiment, was experimentally verified in this paper (detailed in chapter 2).

Wu \& Gonzalez (1998) categorized the different types of Allais paradoxes; they described three common consequence effect conditions: horizontal, vertical, and diagonal shifts within the probability triangle. The first two conditions are shifts in probability mass from the lowest to middle outcomes and middle to highest outcomes, and the third proposed weighting functions. That means individuals violate the independence axiom for small as well as large outcomes, for real as well as hypothetical payoffs, and for small as well as large probabilities, as a result the original expected utility theory is not able to explain choices under risk. They suggested that cumulative prospect theory (CPT) of Kahneman and Tversky can describe all three conditions. Later, Birnbaum (2007) gave an extended and deeply detailed mathematical interpretation of various Allais paradoxes. He suggested a new descriptive model, the transfer of attention exchange model (TAX) and compared it with aforementioned subjectively weighted utility theory (SWU) (Camerer, 1998) and lower gains decomposition utility model (LGDU). He used informational asymmetrical problems (e.g. sellers and buyers in negotiation or bargaining) and represented endowment effects in Allais situations.

This paper will not compare various models of Allais paradoxes. However, Birnbaum's finding (2007) is a possible improvements for this paper. In spite of mathematical terms helping us to underpin common consequences, (probabilities and outcomes are turned into equation), to tell the truth, I absolutely agree with Allais: "The use of even most sophisticated forms of mathematics can never be considered as a guarantee of quality." (Allais, 1988). As a result, in this paper, the original descriptive model was tested empirically with two different owners' positions. It used the classic model of preferences using high payoffs with certain and uncertain outcomes offered to owners or on behalf of another. I applied a static instead of a dynamic model, because according to Andreoni \& Sprenger (2010), risk preferences are not time preferences.

In the classic experiments, no property problems were taken into account, but I was interested in any connections between predictable, seemingly irrational heuristics. The following chapter discusses and details the problem of properties.

\subsubsection{Ownership}

Although actors usually take risks, where the target of the purchases or capital belongs to other actors, i.e. the previous actors, they make decisions about someone else's interests. The relationship of agency is one of the commonest modes of business interactions. However, mainstream economic models do not handle endowment effect or the problem of interests.

Only after the findings of Thaler (1980), was endowment effect widely observed. Endowment effect means that goods one owns are valued higher than other goods not held in endowment. This effect is mostly interpreted (like in the previous chapter) as the result of loss aversion (Kahneman \& Tversky 1979). It seems Kahneman and Tversky work is universal model for both problems. Actors value losses (negatively framed outcome of a risky situation) higher than gains (outcome above the reference point) during the evaluation of choice options. Moreover, if somebody owns a product, the prospect of losing or selling is equal to losses. Dupont \& Lee (2002) tested this wedge, they verified Thaler's findings and they highlighted that the majority of the people questioned in surveys failed to give a price that would compensate them for taking on more risk.

Interestingly, the ownership itself can refer not only to objects. Zoltay Paprika \& Nagy (2012) found that, e.g., the ownership structure of companies played an important role when they examined how creativity was assessed on the job market. Since it was divided into the following categories - Hungarian, foreign and mixed ownership - based on a similar approach, it could be worth examining the endowment effect in international dimensions as well.

Originally, the endowment effect is robust and well-documented in results of experimental economics. This effect introduces a huge gap between the prices at which one is willing to sell or buy a good owned by them. This discrepancy between the maximum willingness to pay for a good and the minimum compensation demanded to part from the good causes a principal agent hierarchical situation.

Moreover, the question is given: What about those who do not own any items but behave as an owner might? The first author who studied this field was Arrow (Arrow, 1984). Based on his theory, Ross (1973) gave a widely mathematical explanation about agency problem. The principal-agent literature is concerned with how the principal (owner) can motivate his/her agent (non-owner) to act in the principal's interests: therefore the principal cannot observe the actions themselves. The agents must choose an action from a number of alternative possibilities (in my research only two possibilities were offered). As Arrow (1984) suggested, the outcome (possibility) is affected - but not completely determined - by the agent's behaviour. Both principal and agent are assumed to be making decisions optionally in view of their own needs. In sum, the agents will play either fair or not fair. Although in this paper principal - agent theory was referred, here can be found a simple hypothetical decision change. My approach, however, differs from that of Arrow (1984) in several ways. The original situation is more complicated. Bakacsi (2015) summarized the characteristics of principal - agent problem which are the following: (1) both the 
agent and the principal manage and control a stock that is important and represents a special surplus for them; (2) the principal owns and control resources and the agent adds value; (3) they have different aims both are selfish and rational that leads to so called opportunistic behaviour; (4) participants made a previous contract based on the bargaining power of the agent but; (5) the agent plays fair or not fair (i.e. he/she is opportunistic). The principal is able to control this problem in three different ways with use of (a) controlling system, (b) motivation and (c) fixed behaviour norms. According to him, this situation is a simple behaviour-economical, decision theory paradigm, where the actors are peers. Reb \& Connolly (2007) underlined that the subjective ownership by independently manipulating factual ownership (i.e., what participants were told about ownership) and physical possession of an object influence each other. Their results showed that the endowment effect might be primarily driven by subjective feelings of ownership rather than by factual ownership. In other words, it the development of a subjective sense of endowment and possession lead actors better, rather than a legal entitlement. Due to this, friendship can serve as a perfect example for subjective sense of endowment. Moreover, Chang et al. (2016) found interactions between altruist and egoist depending on individual heterogeneity. They found that actors (the givers) became more altruistic and willing to help if they know the other subject (the receivers).

Falk et al. (2008) underlined that fair-minded persons are likely to have important economic effects based on their fairness. Because of these issues, it is advantageous to group any agents' behaviour. Hámori (2003) differentiated various types of altruism, here reciprocal altruism was assumed because friendship, businessman' agreement, partnership are typical examples of reciprocal altruism. Small \& Loewenstein (2003) investigated laboratory studies, they maintain that many decisions are driven by arguments or reasons, rather than value-based calculations of options, and friendship is a pretty important reason. They found that determined victims received more money; that means when the victims were determined the subjects donated more money.

Regarding the theories, this paper's groups (roles) are the following:

- Indifferentists or Same safe choices: are those who do not take risk for themselves nor on behalf of a friend. They select the same safe choices two times, i.e. in both cases.

- Good friends: are those who play risky for themselves but avoid risk in place of a good friend (protect their gains).

- The braves or Risk-Takers: are those who take risk in both situations (they are not influenced by the identity of the owner.)

- Agents against principal: avoid risk when they have to decide about their money but they take risk on behalf of their friends.

Table 2 helps us to clarify each groups.

This problem was tested earlier (see Kolnhofer-Derecskei, (2017) - this paper dealt only with the endowment problems, Allais paradox was skipped). Linking Table 1 and Table 2, I was able to measure the connection between endowment effects and Allais paradox.

Conceptual model of this research is presented in Figure 1. The two topics provide two separated hypotheses $(\mathrm{H} 1 ; \mathrm{H} 2)$; a third hypothesis (H3), can be connected and compared to the previous two.

Table 2: Survey variations (Own source)

\begin{tabular}{|c|c|c|c|c|}
\hline Owner & \multicolumn{2}{|c|}{ Self } & \multicolumn{2}{c|}{ Good friend } \\
\hline Situation & Certain & Uncertain & Certain & Uncertain \\
\hline $\begin{array}{c}\text { Same safe choices } \\
\text { INDIFFERENTIST }\end{array}$ & $\mathrm{X}$ & & $\mathrm{X}$ & \\
\hline $\begin{array}{c}\text { Good friends } \\
\text { FRIEND }\end{array}$ & & $\mathrm{X}$ & $\mathrm{X}$ & \\
\hline $\begin{array}{c}\text { Risk taker } \\
\text { BRAVE }\end{array}$ & $\mathrm{X}$ & & $\mathrm{X}$ \\
\hline $\begin{array}{c}\text { Principal agent } \\
\text { AGENT }\end{array}$ & $\mathrm{X}$ & & & $\mathrm{X}$ \\
\hline
\end{tabular}




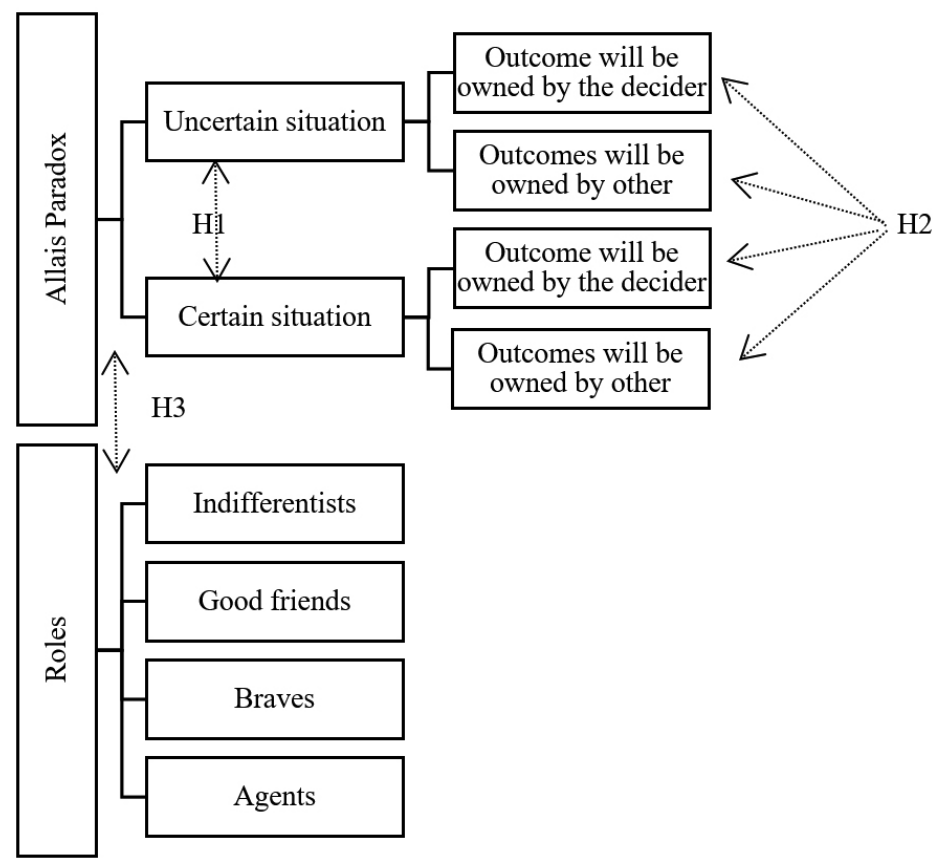

Figure 1: Conceptual model based on theoretical background (Own source)

\section{Methods}

\subsection{Research questions and hypotheses}

Separating the two aforementioned behavioural economics' heuristics allowed the following hypotheses to be tested:

H1. Allais paradox will be interpreted in both cases. There will not be any differences according to who controls the hypothetical outcomes (i.e. the subjects need to decide for themselves or on behalf of their good friend).

H2. The subjects will respond differently when they need to decide about their own interests rather when their friends' interests are concerned. The actors can be identified by the aforementioned types, see Table 2 .

Linking together both above detailed topics, finally the following hypothesis was observed:

$H 3$. When a sure, safe outcome with 1.0 probability is offered to the subjects they take more risk on behalf of their friends and protect their own chances; i.e., they will not be a risk taker on their own behalf (here Allais variant $\mathrm{A}$ ) by comparison with the other Gamble (here Allais variant B).

Due to the sample selection mainly robust (non-sensitive) non parametric test (with significance level 0.05) and symmetric measures were used with SPSS 22.

\subsection{Methods}

The original version was implemented with high hypothetical payoffs. It was used between subjects form; that means the respondents were divided into two groups based on their birthdates. Charness et al. $(2012$, p. 1) defined this technique as the following "In a "between-subject" designed experiment, each individual is exposed to only one treatment. With these types of designs, as long as group assignment is random, causal estimates are obtained by comparing the behavior of those in one experimental condition with the behavior of those in another." They suggested that this design is more likely and preferred in field of social sciences than within-subject design. In this research, the sample was divided into two different groups. this design provides half the amount of information given the sample size but as Charness et al. (2012, p. 8) suggested, "Between analyses are statistically simple to perform as long as random assignment is achieved across groups". In contrast, Birnbaum (2008) advised a different assessment method. According to him, a large number of replications with a large number of properties tested within the same person can only help to analyse personal differences.

On the other hand, Allais followed the between subjects methodology with no replications nor feedback. In this case, one group with even birthdates got the first Allais's gamble (variant A) which also contains a safe sure outcome. The other one (odd birthdates) received the other Allais's gamble version (variant B). Both offers can be seen in Figure 2 and detailed in the aforementioned Table 1. The 


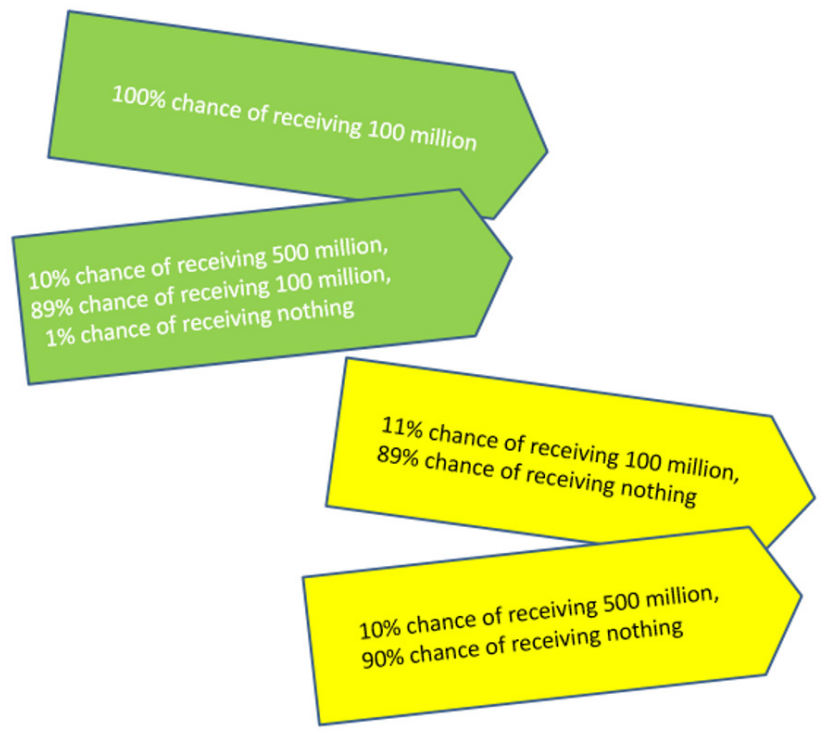

Figure 2: Allais' gambles (Own source)

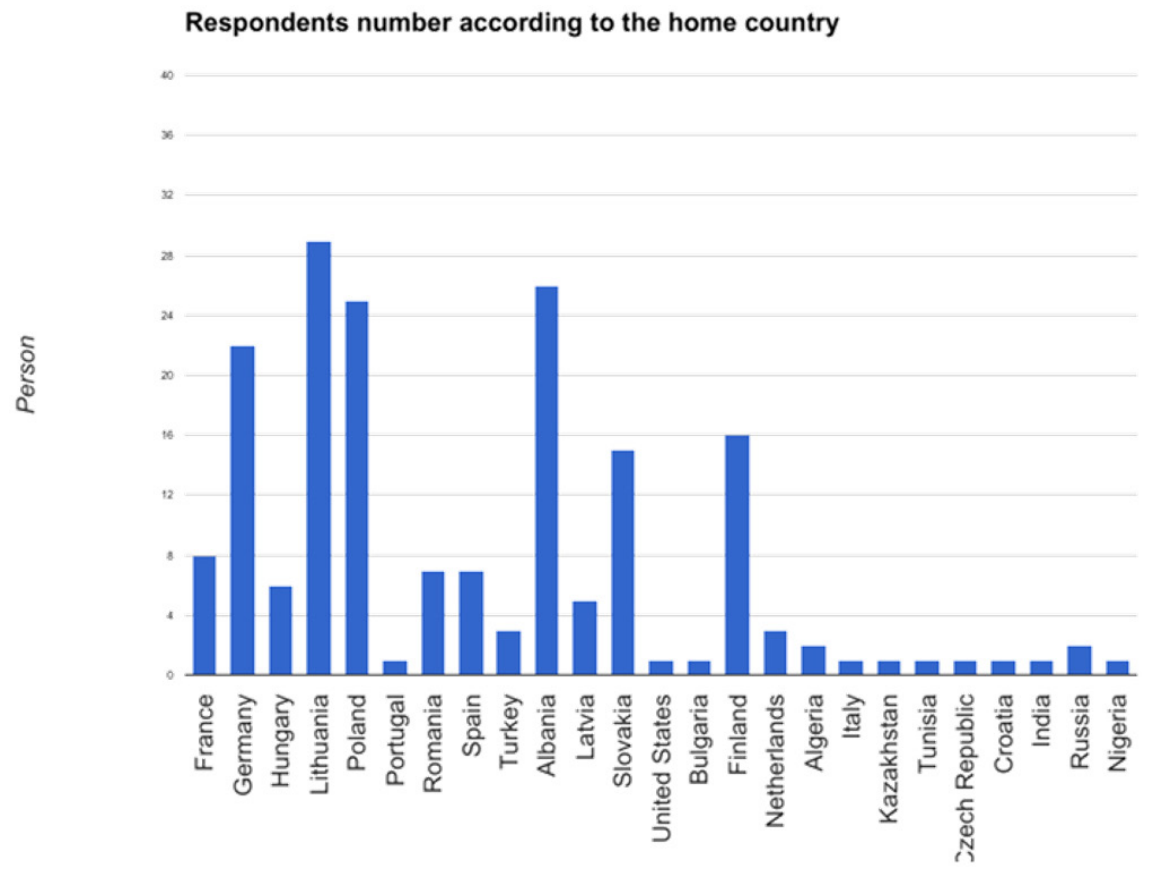

Figure 3: Sample statistics regarding ethnicity (capita) (Own source)

experiment was a between-subjects survey (two groups) and the classic version with high hypothetical payoffs was used. It took place online (so called lab experiment situation). No feedback or reputation possibilities were given to the subjects.

This experiment was only a part of a wider research. A pilot version was tested and evaluated earlier (see Kol-
nhofer-Derecskei (2017)) and the original text can be found in the Appendix. The survey (i.e. Google Form) was shared electronically among the partner universities of Obuda University Keleti Faculty of Business and Management; original, whole texts of the questionnaire can be reached on the Internet ${ }^{1}$. 


\subsection{Sample}

After clearing and clarifying data, the evaluated number of answers is 186. As mentioned earlier, my chosen population (target group) was university students studying at any partner university (see Figure 1). It is a fact that current university students will be future employees, and higher education institutions are facing serious challenges all over Europe. As well as the high rate of unemployment, lack of professionals, the decrease in the number of younger generations, the expected quality and content of knowledge has also changed. Therefore, we need to know their behaviour (Kádár-Reicher 2016).

However, the sample was multicultural (different ethnicities) but the subsamples' sizes do not allow concentration on national comparisons.

The subjects were divided into two groups according to the date of birth (even number variant A contains 89 persons, odd number variant $\mathrm{B}$ has 97 persons). The minimum age of respondents was 19 years old, the maximum 57 years, and an average of 24.51 years of age. There were 80 males and 106 females. Overwhelmingly, respondents were studying business $(n=124)$ or engineering $(n=52) ; 10$ persons were from other faculties. Study levels are the following: 121 persons attend bachelor full-study programs; 60 persons master studies and there were five doctoral students.

\subsection{Hypotheses testing}

In this chapter, any hypotheses are being tested step by step.

H1. Allais paradox will be interpreted in both cases. There will not be any differences according to those who modelled the hypothetical outcomes (i.e. the subjects need to decide for themselves or on behalf of their good friend).
Comparing both gamble variations, there were no significant differences between them regarding the ownership. As a result, almost the same distribution can be seen in Table 3. Most of the subjects chose the first safe option in the first gamble and in the frame of the second variant they preferred the second one. That mirrors Allais' original findings. In both cases there was significant symmetrical measurement, but weak connections were found e.g. Cramer $0.223(\mathrm{p}=0.02)$.

H2. The subjects respond differently when they need to decide about their own properties rather when their friends' properties are concerned. The actors can be divided related to the aforementioned types, see Table 2.

All the aforementioned roles (types of subjects) can be identified with the following frequencies (see Table 4). Around 70 percent of the subjects chose the same options for themselves and on behalf of their friends, half of them voted for the risky (certain) and another half for the uncertain (not risky) outcomes.

Relating tp Huck \& Müller (2012), I was interested in gender differences as well. Although there were no significant differences (using non-parametric Mann-Whitney test sig. level 0.05 Asym. sig $p=0.199$ ), the crosstabs analysis could be interesting because men (males) took risk more often (see Table 5). But Da Silva and colleagues findings cannot be verified.

H3. When a sure safe outcome is offered to the subjects they take more risk on behalf of their friends and protect their own win (i.e. they will not be risk taker on behalf of themselves, here Allais variant A) compared with the other gamble (here Allais variant $\mathrm{B}$ ).

This hypothesis can be accepted as well, because in the A

Table 3: Frequencies of Allais (capita) (Own sources)

Number of respondents

\begin{tabular}{|c|c|c|c|c|}
\hline Allais A & Winnings & Probability & Self & Good friend \\
\hline Gamble A & 100 & 1 & 61 & 61 \\
\hline \multirow{3}{*}{ Gamble B } & 100 & 0.89 & \multirow{3}{*}{28} & \multirow{3}{*}{52} \\
\hline & 500 & 0.1 & & \\
\hline & 0 & 0.01 & & \\
\hline Allais B & Winnings & Probability & Self & Good friend \\
\hline \multirow{2}{*}{ Gamble C } & 100 & 0.11 & \multirow{2}{*}{45} & \multirow{2}{*}{43} \\
\hline & 0 & 0.89 & & \\
\hline \multirow{2}{*}{ Gamble D } & 500 & 0.1 & \multirow{2}{*}{52} & \multirow{2}{*}{54} \\
\hline & 0 & 0.9 & & \\
\hline
\end{tabular}


Table 4: Crosstabs according roles (capita) (Own source)

\begin{tabular}{|c|c|c|}
\hline Roles & Frequency & Percent (distribution) \\
\hline Agent & 23 & 12.4 \\
\hline Indifferent & 74 & 39.8 \\
\hline Good friend & 30 & 16.1 \\
\hline Risk taker & 59 & 37.7 \\
\hline Total & 186 & 100 \\
\hline
\end{tabular}

Table 5: Crosstabs according gender and roles (capita) (Own source)

\begin{tabular}{|c|c|c|c|}
\hline \multirow{2}{*}{ Roles } & \multicolumn{2}{|c|}{ Gender } & \multirow{2}{*}{ Total } \\
\cline { 2 - 3 } & Male & Female & \\
\hline Agent & 7 & 16 & 23 \\
\hline Indifferent & 32 & 42 & 74 \\
\hline Good friend & 12 & 18 & 30 \\
\hline Risk taker & 29 & 30 & 59 \\
\hline Total & 80 & 106 & 186 \\
\hline
\end{tabular}

Table 6: Crosstabs according roles and Gamble Variant (capita) (Own source)

\begin{tabular}{|c|c|c|c|}
\hline \multirow{2}{*}{ Roles } & \multicolumn{2}{|c|}{ Allais variant } & \multirow{2}{*}{ Total } \\
\cline { 2 - 3 } & A & B & \\
\hline Agent & 9 & 14 & 23 \\
\hline Indifferent & 43 & 31 & 74 \\
\hline Good friend & 18 & 12 & 30 \\
\hline Risk taker & 19 & 40 & 59 \\
\hline Total & 89 & 97 & 186 \\
\hline
\end{tabular}

case (with sure outcome) most subjects $(18+43=61$ person) voted for the certain outcome rather than in B (uncertain) gamble $(n=12+31=43)$. Other connections (e.g. relationships with level of studies or main subjects) were not confirmed.

\section{Discussion}

The goal of this paper is then twofold. First, it was established a conceptual link between Allais-type behaviour and ownership problem. Second, Allais axiom was used to characterize different roles. Since the original Allais experiment, several variations were tested, some of them are detailed above, and others are only mentioned.

Nonetheless, in this paper the subjects faced with the original Allais situation. This research investigated how the subjects behave in the same situation but on behalf of their friends, so the Allais paradox (widely heuristics) and ownership problem (widely endowment economy) were connected.
Earlier also Birnbaum's paper (2007) proposed endowment effect and Khalil (2015) dealt with principal and agent framework, as well. I agree with Khalil's explanation "The principal and the agent have identical preferences. They differ only with respect to their beliefs. The principal's beliefs are optimal in the sense of being the best given the information. The agent's beliefs are suboptimal; they are based on over-estimation of the likelihood of success. Consequently, the agent recommends to the individual impulsive (suboptimal) actions, while the principal recommends to the individual optimal decisions." (p. 558).

Because my results underlined it, summary of the results can be found in Table 7 .

Finally yet importantly, we must ask what the reasons are for the Allais paradox also happening when the subjects take risk on behalf of somebody else. According to Oliver (2003), I summarized some possible explanations for Allais effect.

The first explanation is the classic Kahneman \& Tversky's loss aversion effect (prospect theory). These Nobel 
Table 7: Hypotheses testing (Own resources)

\begin{tabular}{|l|c|}
\hline \multicolumn{1}{|c|}{ Hypotheses } & Results \\
\hline H1. Allais paradox was be interpreted in both cases. & Accepted \\
\hline $\begin{array}{l}\text { H2. The subjects responded differently when they needed to decide about their } \\
\text { own properties rather when their friends' properties were concerned. }\end{array}$ & Accepted \\
\hline $\begin{array}{l}\text { H3. When a sure safe outcome was offered to the subjects, they took more risk } \\
\text { on behalf of their friends rather than own. }\end{array}$ & Accepted \\
\hline
\end{tabular}

Prize-winning authors presented a critique of expected utility theory as a descriptive model of decision making under risk and developed an alternative model. According to their work, people tend to avoid risk when a positive frame is presented, but they seek risks if a negative frame is utilized. This effect may be strong in the choice between the two situations. The subjects have the possibility to avoid the possibility of winning nothing. The amount of money offered is quite high and serves as a reference point.

The second reason can be that when certainty is anticipated, disappointment may confuse the original expected utilities. This cognitive process applies to probabilities rather than the outcomes. My findings indicate that certain and uncertain consumption are evaluated differently; I found significant differences between risky (uncertain) and non-risky (certain) Allais variations. The perceived level of risk also influences our decision; making a decision under risk, where the possibility of losing our ownership is higher than the risk taken on behalf of our friend, makes us risk averse and confuses our preferences.

In this experiment, significant differences can found between deciding for ourselves and deciding in place of a friend. My findings assume that people decide systematically in different ways about their own property rather than about others'. They are more risk averse when the outcome is theirs but will take risk on behalf of others. At the same time, this verifies the Agent- Principal Theory and the Endowment effect.

In the results, I need to underline that in the second situation the safe wins were more attractive for the subjects than the feeling of risk. Due to this, in variant B they focused more on the amount of safe winnings (i.e. USD) than the probability of win options (i.e. percentage). In the case of variant $\mathrm{A}$, it was reversed.

\section{Limitations of the study}

I agree with Huck \& Müller (2012) that "it appears that lab results will draw a too optimistic picture. The population at large, it turns out, is less consistent with EUT than student samples are." (p. 276). Van de Kuilen \& Wakker (2006) summarized the limitations of Allais paradox, as they said, "our study gives the first pure demonstration that irrationalities such as in the Allais paradox are less pronounced than often thought" (p. 155). As it was underlined earlier, it is typical that the subjects had never faced these situations before, so their decisions could be based on simple misunderstandings or misinterpretations rather than on irrationalities. Thinking in probabilities is also unfamiliar for the subjects. Most of the experiments (like the present paper) use poor descriptions instead of any visually or numerically understandable overview. Hertwig et al. (2004) called this form 'decision from description'. They proposed, "decisions from experience and decisions from description can lead to dramatically different choice behavior." (Hertwig et al. 2004, p. 534). Their results suggest that direct experience of outcomes leads to underweighting, i.e., in decisions based on experience, rare events had less impact than in decisions from descriptive. At the same time, theoretical and hypothetical choices do not motivate subjects to reveal their true preferences. Fan (2002) tested three small-payoff variants on the Allais paradox questions. For each variant, the probabilities were the same as in the original Allais questions; only the payoffs differed. There were both hypothetical and real payoffs and also negative payoffs. She found that whether payoffs were hypothetical or real, Allais paradox behaviour largely disappeared. As she summarized the behaviour was closer to simple expected value maximization when payoffs were real than when they were hypothetical.

Other side of the coin is that altruistic behaviour can be motivated. Fehr \& Fischbacher (2003) highlighted the interaction between altruists and selfish subjects with human cooperation. Because a minor group of altruists can force a majority of selfish subjects to cooperate or, conversely, a few egoists can influence a large number of altruists to defect. They tested the effect of punishment and reward in case of altruism. Calabuig et al. (2016) investigated effect of punishment in an experiment with endowment heterogeneity. Using within-subjects designs they found that endowment effect disappear with punishment. Therefore, punishment has an opposite psychological effect on intrinsic motivation. Friendship and subjective positive feelings between owners and decision makers improve rationality through shared responsibility (e.g. unwritten businesspersons' agreement).

According to Camerer (1998), some studies concentrated on fitting theories to individuals. As it was mentioned earlier risk taking preferences might be take in 
account, Palmer et al. (2013) detailed how individual differences can be measured but they mentioned cross cultural differences, as well. Baillon et al. (2016) compared the rationality of group decisions with individual decisions under risk. Participants were required to choose between two options that based on Allais problem. They found that communication helped to find more moral rational decisions, and the groups violated less axioms and were more rational than individuals did. It seems that group decision drives to more rational choices because solves the feeling of uncertainty. It should be underlined that some researchers confuse risk and uncertainty (like Robison at al. (2010) used the terms: decision under uncertainty, in contract Kahneman \& Tversky (1979 used decision under risk) but they are not equal to each other. In this paper these two phenomena will not be differed (please find it detailed in

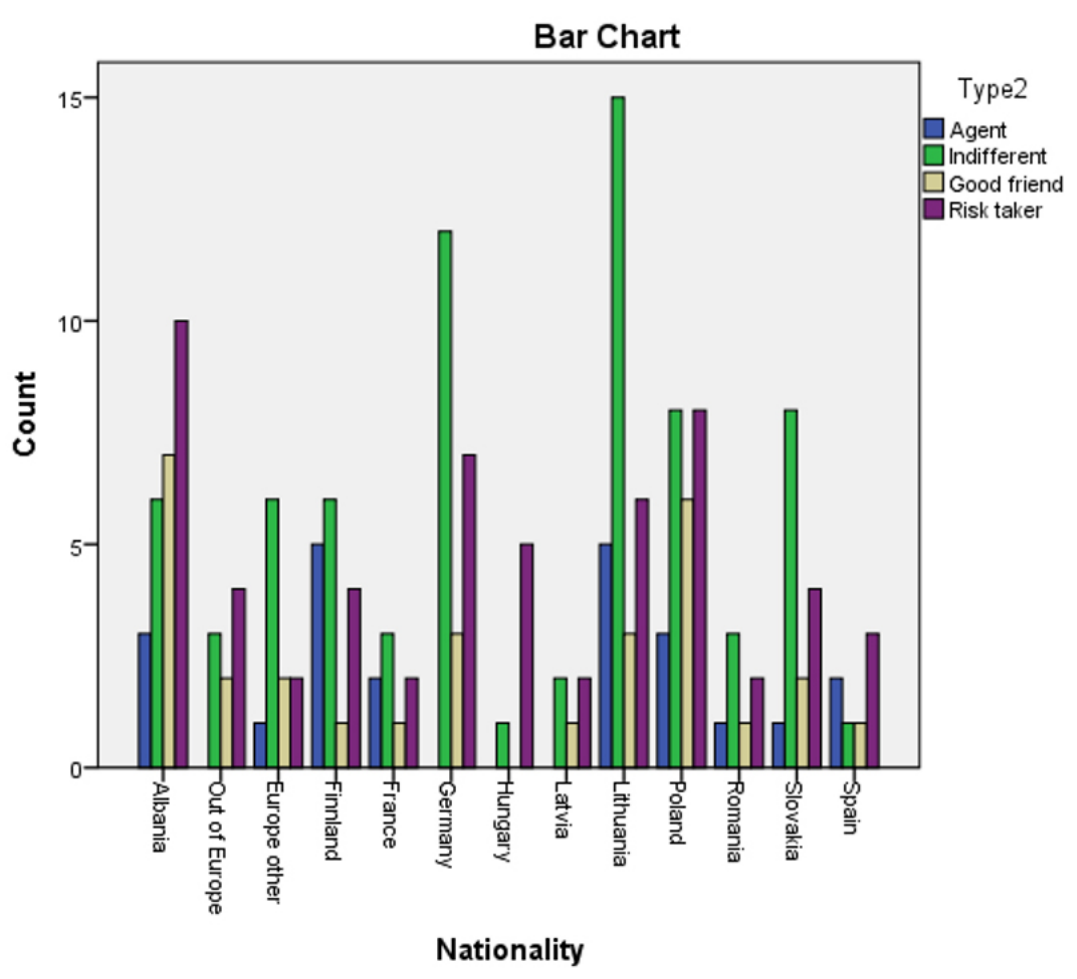

Figure 4: Sample statistics regarding ethnicity (capita) (Own resources)

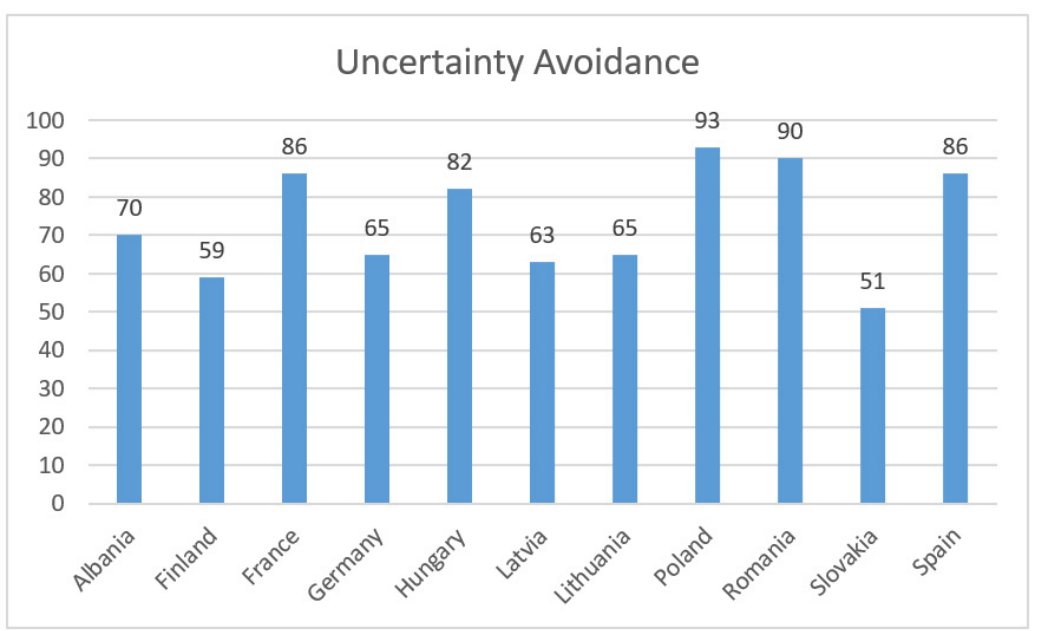

Figure 5: Sample statistics regarding ethnicity (capita) Based on Hofstede Centre's results) 
Kolnhofer-Derecskei \& Nagy 2017). Here I just agree with Andreoni \& Sprenger (2010) that Allais problem might be connected with uncertain and certain effect. Managing uncertainty among different cultures is measured by Hofstede (2017). In his definition, uncertainty is the following: "The Uncertainty Avoidance dimension expresses the degree to which the members of a society feel uncomfortable with uncertainty and ambiguity." (Hofstede, 2017). UA Indexes of participants are indicated in Figure 4. These results based on findings of Hofstede's Centre ${ }^{2}$.

In this paper, ethnicity was related to the different roles. That means there were significant differences in both cases (i.e. Group A and Group B) regarding nations. (Kruskal-Wallis with sig. level $0.05 \mathrm{p}<0.005$ ). However, these results can be caused by the non representative sample selection methods. Descriptive histograms in Figure 4 show some differences among participants' cultural backgrounds.

Comparing Figures 4 and 5, it can be realized that in case of Albania (where the number of the participants was also acceptable) should be some relationship. UA Index is not so high which can explain the salient number of risk-takers.

\section{Conclusion}

Yet, what is the evidence of this paper? The importance of learning and knowledge helps us to avoid irrationalities due to basic misunderstanding and lack of motivation. As Birnbaum (2008) suggested a long experiment is possible that people might learn stochastics evidences.

That is the reason why it is useful to observe this old-fashioned effect. If we find predictable patterns of irrationality in human behaviour, then we can improve economic theory. I agree with Maletič et al. (2017) that the increasing turbulent business environment means that organizations are constantly faced with either uncertain and/ or competitive environments. Hence it is recommended to adopt and use such kind of managerial practices (e.g. Maletič et al. (2017) suggested PAM) and KPIs which help and control uncertain and risky decisions.

Closing this chapter, I would quote Herbert Simon (1978 p. 361), who said the following in his Nobel lecture "I have perhaps said enough also with respect to the limitations of these new constructs to indicate why I do not believe that they solve the problems that motivated their development." I hope that this paper helps to understand how psychological issues can improve decision makers in a business area.

\section{Anknowledgement}

This research was supported by the ÚNKP-16-4/III. and ÚNKP-17-4/1 New National Excellence Program of the Ministry of Human Capacities. The author is thankful for the help of Prof. Wlodzimierz Sroka.

\section{References}

Allais, M. (1988, December 9). An Outline of My Main Contributions to Economic Science. Lecture notes distributed in Nobel Lectures. France, Paris. http:// www.nobelprize.org/nobel_prizes/economic-sciences/laureates/1988/allais-lecture.html, http://dx.doi. org/10.1007/BF00134634

Andreoni, J., \& Sprenger, C. (2010). Certain and Uncertain Utility. The Allais Paradox and Five Decision Theory Phenomena. Levine's Working Paper Archive 926159295. https://pdfs.semanticscholar.org/83da/ed55d89ad8d0b94ac72e509dbb118983f069.pdf

Arrow, K. J. (1984). The Economics of Agency. Stanford University: A Report of the Center for Research on Organizational Efficiency, www.dtic.mil/get-tr-doc/ pdf?AD=ADA151436

Bakacsi, Gy. (2015). Változó vezetési paradigma - változó megbízó ügynök probléma? [Changing leader-paradigm - changing principal-agent problem?] In Bakacsi, Gy. -Balaton, K. (Eds.): Vezetés és szervezet társadalmi kontextusban: Tanulmányok Dobák Miklós 60. születésnapja tiszteletére. Budapest, Akadémiai Press, 29-54.

Baillon, A., Bleichrodt, H., Liu, L., \& Wakker, P. P. (2016). Group Decision Rules and Group Rationality under Risk. Journal of Risk and Uncertainty. 52(3), 99-116, http://dx.doi.org/10.1007/s11166-016-9237-8

Birnbaum, M. H. (2007). Tests of branch splitting and branch-splitting independence in Allais paradoxes with positive and mixed consequences. Organizational Behavior and Human Decision Processes, 102, 154173, http://dx.doi.org/10.1016/j.obhdp.2006.04.004

Birnbaum, M., H. (2008). New Paradox of Risky Decision Making. Psychological Review. 115(2), 463-501.

Calabuig, V., Fatas, E., Olcina, G. \& Rodriguez-Lara, I. (2016). Carry a big stick, or no stick at all Punishment and endowment heterogeneity in the trust game. Journal of Economic Psychology, 157, 153-171, http://dx. doi.org/10.1016/j.joep.2016.09.006

Camerer, C. (1998). Bounded Rationality in Individual Decision Making. Experimental Economics. 1, 163-183.

Charness, G., Gneezy, U., \& Kuhn M. A. (2012). Experimental methods: Between-subject and within-subject design. Journal of Economic Behavior \& Organization. 81(1), 1-8, http://dx.doi.org/10.1016/j.

2 Secondary data are downloaded from https://geert-hofstede.com/countries.html on 05/2017 
jebo.2011.08.009

Chang, S., Dee, T. S., Tse, C. W., \& Yu, L. (2016). Be a Good Samaritan to a Good Samaritan: Field evidence of other-regarding preferences in China. China Economic Review, 41, 23-33, http://dx.doi.org/10.1016/j. chieco.2016.08.007

Da Silva, S., Baldo, D., \& Matsushita, M. (2013). Biological correlates of the Allais paradox. Applied Economics, 45(5). 555-568, http://dx.doi.org/10.1080/000368 46.2011 .607133

Dupont, D., Y. \& Lee, G., S. (2002). The Endowment Effect, Status Quo Bias and Loss Aversion: Rational Alternative Explanation. The Journal of Risk and Uncertainty, 25(1), 87-101.

Falk, A., Fehr, E., \& Fishbacher, U. (2008). Testing theories of fairness-Intentions matter. Games and Economic Behavior, 62(1), 287-303, https://doi.org/10.1016/j. geb.2007.06.001

Fan, Ch. (2002). Allais paradox in the small. Journal of Economic Behavior \& Organization, 49, 411-421, http://dx.doi.org/10.1016/S0167-2681(02)00012-4

Fehr, E., \& Fischbacher, U. (2003). The nature of human altruism. Nature, 425, 785-791. http://dx.doi. org/10.1038/nature02043

Hámori, B. (2003). Érzelemgazdaságtan, Budapest, Kossuth Press.

Hertwig, R., Barron, G., Weber, E. U. \& Erev, I. (2004). Decisions from Experience and the Effect of Rare Events in Risky Choice. Psychological Science, 15(8), 534 - 539, https://doi.org/10.1111/j.09567976.2004.00715.x

Hofstede, G. (2017). The Hofstede Centre [Online]. Retrieved February 2017 from https://geert-hofstede.com

Huck, S., \& Müller, W. (2012). Allais for all: Revisiting the paradox in a large representative sample. Journal of Risk and Uncertainty, 44(3), 261-293, http://dx.doi. org/1007/s11166-012-9142-8

Maletič, D., Maletič, M., Al-Najjar, B., Gotzamani, K., Gianni, M., Kalinowski, T., B. \& Gomišček, B. (2017). Contingency Factors Influencing Implementation of Physical Asset Management Practices. Organizacija, 50, 3-16, http://dx.doi.org/10.1515/orga-2017-0003

Kádár, B. \& Reicher, R. Z. (2016). Education Supported by SME vs. SME Supported by Education. Proceedings of FIKUSZ 2016 Budapest, 73-79.

Khalil, E. L. (2015). Temptations as Impulsivity: How far are Regret and Allais Paradox from Shoplifting? Economic Modelling, 51, 551-559, http://dx.doi. org/10.1016/j.econmod.2015.09.016

Kolnhofer-Derecskei, A., \& Nagy, V. (2017). Comparing risk definitions giving by Hungarian and Belgian Bachelor Students. Thinking together. In Press.

Kolnhofer-Derecskei, A., \& Nagy, V. (2016). Under Risk. Proceedings of FIKUSZ '16 Symposium for Young Researchers, 161-172.
Retrieved February 2017 from https://kgk.uni-obuda. hu/sites/default/files/16_Derecskei_Nagy.pdf

Kolnhofer-Derecskei, A. (2017). How would you decide on behalf of your friend? Takács, I. (Eds). Management, Enterprise and Benchmarking in the 21 st century "Global challenges, local answers" Budapest, Obuda University. 195-205. Retrieved July 2017 from http://kgk.uni-obuda.hu/publikaciok/management-enterprise-benchmarking-IV

Oliver, A. (2003). A quantitative and qualitative test of the Allais paradox using health outcomes. Journal of Economic Psychology, 24, 35-48, http://dx.doi. org/10.1016/S0167-4870(02)00153-8

Palmer, C. J., Paton, B., Ngo, T. T., Thomson, R. H., Hohwy, J., \& Miller, S., M. (2013). Individual Differences in Moral Behaviour: A Role for Response to Risk and Uncertainty? Neuroethics, 6, 97-103, http:// dx.doi.org/10.1007/s12152-012-9158-4

Reb, J., \& Conolly, T. (2007). Possession, feelings of ownership and the endowment effect. Judgment and Decision Making, 2(2), 107-114.

Robison, L. J., Shupp, R. S., \& Myers, R. J. (2010). Expected Utility Paradoxes. The Journal of Socio-Economics, 39, 187-193, http://dx.doi.org/10.1016/j.socec.2009.12.005

Ross, S., A. (1973). The Economic Theory of Agency: The Principal's Problem. American Economic Review, 63(2), 134-39. Retrieved February 2017 from http:// www.jstor.org/stable/1817064?origin=JSTOR-pdf

Simon, H. (1971). Designing Organizations for an Information-rich World. In Greenberger, M. (Eds.) Computers, Communications and the Public Interest. The Johns Hopkins Press, pp. 38-72.

Simon, H. (1978). Rational Decision-Making in Business Organization. Nobel Memorial Lecture. $8^{\text {th }}$ of December 1978.

Small, D., \& Loewenstein, G. (2003). Helping a Victim or Helping the Victim: Altruism and Identifiability. The Journal of Risk and Uncertainty, 26(1), 5-16.

Thaler, R. H. (1980). Toward a Positive Theory of Consumer Choice. Journal of Economic Behavior \& Organization 1(1), 39-60, http://dx.doi.org/10.1016/01672681(80)90051-7

Tversky, A., \& Kahneman, D. (1974). Judgement under Uncertainty: Heuristics and Biases. Science, New Series, Vol. 185, No. 4157. (Sep. 27, 1974), pp. 11241131, http://links.jstor.org/sici?sici=0036-8075\%2819 740927\%293\%3A185\%3A4157\%3C1124\%3AJUUHAB\%3E2.0.CO\%3B2-M

Van de Kuilen, G. \& Wakker, P. P. (2006). Learning in the Allais paradox. Journal of Risk and Uncertainty. 33(3), 155-164, http://dx.doi.org/10.1007/s11166-006-03903

Wu, G. \& Gonzales, R. (1998). Common Consequence Conditions in Decision Making under Risk. Journal of 
Risk and Uncertainty, 16, 115-139.

Zoltay Paprika, Z., \& Nagy, V. (2012). Assessment of Creativity on the Job Market. Procedia Economics and Finance, 3, 166-181, http://dx.doi.org/10.1016/S22125671(12)00136-0
Anita Kolnhofer-Derecskei is working as Assistant Professor at Óbuda University in Budapest, Hungary. She teaches various courses on business economics and management, statistics and research methodology on bachelor, master and $\mathrm{PhD}$ level. Her research interest includes economic psychology and behavioural economics. Her research work and PhD dissertation focused on the organizational creativity in 2015. As a member of some scientific committees and journals' guest editor, she participated in more national research projects and two times won the Hungarian New National Excellence Program's internship. 


\section{Appendix}

Allais variant $A$ (if the birthday number of the respondents is even)

Suppose you have just won 100 million USD in a gamble. What would you do?

It's up to you whether you

- keep a sure gain of 100 million USD and quit the game OR

- you go on, continue the gamble, where there's a $10 \%$ chance of 500 million; $89 \%$ chance of 100 million; $1 \%$ chance of nothing.

Suppose one of your best friends is in the same situation but you have to decide instead of him/her. Which would you choose for him/her?

- He/She has to quit and keep a sure gain of 100 million USD

- He/She has to continue the gamble with the before mentioned assumptions / conditions.

Allais variant $B$ (if the birthday number of the respondents is odd)

Two gambles are offered to you but you can take part only in one of them. Which do you prefer?

- With a $11 \%$ chance you win 100 million USD and with a $89 \%$ chance you win nothing OR

- There's a $10 \%$ chance that you win 500 million USD and an $90 \%$ chance that you win nothing.

Suppose one of your best friends is in the same situation but you have to decide instead of him/her. Which would you choose for him/her?

- With a $11 \%$ chance he/she wins 100 million USD and with a $89 \%$ chance he/she wins nothing OR

- There's a 10\% chance that he/she wins 500 million USD, and $90 \%$ chance that he/she wins nothing. 